\title{
Trabalho Cooperado na Suinocultura: Emancipação ou Precarização?
}

Cooperative Work in Pig Farming: Emancipation or Insecurity? Trabajo Cooperado en la Cultura Suína: Emancipación o Deterioro?

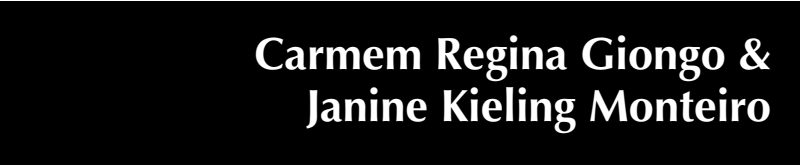

Universidade do Vale do Rio dos Sinos

http://dx.doi.org/10.1590/1982-3703002182013

(cc) BY 
Resumo: Este estudo teve o objetivo de analisar as vivências de prazer e sofrimento de suinocultores frente ao modelo de trabalho cooperado. Também buscou caracterizar o trabalho cooperado na suinocultura, além de compreender as estratégias defensivas utilizadas. O estudo teve um delineamento qualitativo e contou com a participação de 16 suinocultores. A coleta foi realizada através de dois grupos focais e de observações. Os dados obtidos através dos grupos focais foram submetidos à análise de conteúdo. As vivências de sofrimento se mostraram atreladas ao crescimento da cooperativa através da exploração dos cooperados, à falta de autonomia e de espaços públicos de fala, aos controles excessivos de qualidade e produtividade, e principalmente, ao precário modelo de remuneração praticado. Diante destes fatores foram identificadas estratégias defensivas pautadas na submissão e no individualismo, o que tem desencadeado experiências de solidão, desesperança e insegurança frente ao futuro. Os participantes não reconheceram vivências de prazer frente ao trabalho cooperado. Através dos resultados obtidos, concluiu-se que o modelo vigente de cooperativismo se apresenta como um fator de precarização, intensificando o processo de sofrimento mental e deixando de contribuir para a emancipação e desenvolvimento dos suinocultores.

Palavras-chave: Psicoterapia Psicodinâmica. Trabalho. Saúde Mental.

Abstract: This study aimed to analyze the experiences of pleasure and suffering of pig farmers in relation to the cooperative work model. It also demonstrated the characteristics of cooperative work in pig farming and understanding of the defensive strategies used. The study utilized a qualitative research design involving 16 pig farmers. The collection of data was conducted through two focus groups as well as observations. The data obtained from the focus groups were subjected to content analysis. The experience of suffering is shown to be tied to the growth of the cooperative through the exploitation of its members, the lack of autonomy and public speech places, the excessive control of quality and productivity, and especially to the precarious remuneration model used. Thus, defensive strategies were identified, guided by submission and individualism, culminating in loneliness, hopelessness, and insecurity toward the future. The participants did not show any pleasure toward the cooperative work. In accordance with the results obtained, we conclude that the cooperative work of pig farming presents itself as a factor of instability and intensifies the mental suffering process that fails to contribute to workers' emancipation.

Keywords: Psychotherapy, Psychodynamic. Work. Mental Health.

Resumen: Este estudio tuvo como objetivo analizar las buenas y malas experiencias de los criadores de cerdos fuera del modelo de trabajo cooperativo. También trató de caracterizar el trabajo cooperativo de los criadores de cerdos y comprender las estrategias defensivas utilizadas. El estudio tuvo un diseño de investigación cualitativa, con la participación de 16 productores porcinos. Los datos fueron recolectados a través de dos grupos focales y observaciones. Los datos obtenidos a partir de los grupos de enfoque fueron sometidos a análisis de contenido. Las malas experiencias de los criadores aparecen ligadas al crecimiento de la cooperativa a través de la explotación de los miembros, la falta de autonomía y de espacios abiertos para discusión sobre tales experiencias, el excesivo control de la calidad y la producción, y en especial, el precario modelo de remuneración practicado. Teniendo en cuenta estos factores se identificaron estrategias defensivas orientadas por la sumisión y el individualismo, que ha dado lugar a experiencias de soledad, desesperanza e inseguridad hacia el futuro. Los participantes no reconocen experiencias positivas en el ambiente de trabajo cooperativo. De los resultados, se concluyó que el actual modelo de cooperación se presenta como un factor de inestabilidad que intensifica el proceso de sufrimiento mental y que deja de contribuir con la capacitación y el desarrollo de los criadores de cerdos.

Palabras clave: Psicoterapia Psicodinámica. Trabajo. Salud Mental. 


\section{Introdução}

As cooperativas tiveram origem no Brasil através da organização coletiva dos trabalhadores nos anos 1980 diante do desemprego formal e também da reestruturação econômica. $\mathrm{O}$ movimento foi impulsionado pelas políticas neoliberais no governo Collor, gerando flexibilização pela ausência de contrato de trabalho e maior responsabilização do trabalhador (Lima, 2009). Dentre os diversos tipos de cooperativas, destacam-se aquelas nas quais ocorre a venda de mão de obra para terceiros e aquelas em que as pessoas se organizam para gerar renda a partir da fabricação de algum produto (Oliveira, 2007).

No Brasil, o debate sobre as cooperativas é polêmico e está pautado em dois modelos diferentes: por um lado, o "cooperativismo autêntico", apoiado pela Economia Solidária e caracterizado pela utilização dos princípios da autogestão e emancipação dos trabalhadores; por outro, o "cooperativismo tradicional" que segue uma orientação de mercado, inserindo-se em uma perspectiva empresarial, representado pela Organização das Cooperativas Brasileiras (Lima, 2009, p. 113). Apesar das diferenças, estes dois modelos estão amparados pelos mesmos fundamentos legais, representados pelas Leis $\mathrm{n}^{\circ}$ 5.764/1971 e no 12.690/2012 (Brasil, 1971; 2012a), as quais instituem requisitos como: gestão democrática; autonomia e independência dos cooperados; educação, formação e informação; preservação dos direitos sociais, do valor social do trabalho e da livre iniciativa; e não precarização do trabalho.

Com a expansão do cooperativismo, muitas empresas industriais e agrícolas, com o intuito de reduzirem os custos da aplicação do trabalho humano, criaram cooperativas visando à intermediação de mão de obra (Oliveira, 2007). Algumas cooperativas passaram a ser geridas pelas empresas contratantes, tornando-se um instrumento de precarização através da substituição da atividade assalariada regular, pelo trabalho autônomo (Singer, 2004). Este cenário justifica as inúmeras críticas direcionadas ao cooperativismo, principalmente porque em muitos casos as cooperativas fazem uso de uma legislação e ideologia que facilita a exploração e a submissão dos trabalhadores, ao invés de seu desenvolvimento e emancipação (Carelli, 2002; Lima, 2004; Oliveira, 2007; Singer, 2004).

A expansão, ou, como mencionado por Singer (2004), o verdadeiro "surto" de cooperativas, também ganhou força no meio rural, impulsionado, do mesmo modo, pela reestruturação e globalização da economia (Martinez, Lins \& Pires, 2002). Conforme dados do Serviço Nacional de Aprendizagem do Cooperativismo (SESCOOP, 2011), o ramo agropecuário é líder nacional na quantidade de cooperativas, acumulando aproximadamente 969.541 cooperados distribuídos em 1.523 organizações, que são responsáveis por prover $40 \%$ do Produto Interno Bruto (PIB) agrícola (FAO, 2012). Neste meio, uma atividade marcada pelo modelo de trabalho cooperado é a suinocultura, que, atualmente, tem mais de $75 \%$ dos suinocultores brasileiros vinculados a cooperativas que intermediam a relação destes trabalhadores com a agroindústria, caracterizando-se como cooperativas de mão de obra (Paraná, 2013).

A suinocultura é considerada uma atividade de alta tecnologia, realizada por propriedades rurais pequenas ou médias, e inserida em uma complexa cadeia produtiva. A produção integrada ocorre através do fornecimento de insumos, tecnologias, métodos e procedimentos de trabalho por parte das indústrias processadoras de alimentos ao suinocultor que, por sua vez, produz e entrega o suíno desenvolvido para o abate. O papel das cooperativas neste cenário é o de intermediar a venda dos animais produzidos pelo produtor rural à agroindústria (Paraná, 2013) . Atualmente, o Brasil está posicionado no quarto lugar do ranking mundial de produção e exportação de carne suína, com crescimento de 8\% no ano de 2012 (Brasil, 2012b). Na região sul, a suinocultura está entre as atividades mais importantes, representando $50 \%$ da produção brasileira, tendo o estado de Santa Catarina como o maior produtor nacional, seguido pelo Paraná e Rio Grande do Sul (Embrapa, 2012; Paraná, 2013). 
Apesar da crescente ampliação e representatividade econômica da suinocultura no Brasil e no mundo, estudos nacionais e internacionais têm focado suas investigações no levantamento dos riscos físicos associados à atividade, apontando para uma escassez de investigações acerca da organização do trabalho na suinocultura e da saúde mental deste grupo de trabalhadores (Cole, Hill, Humenik \& Sobsey, 1999; Donham, 2010; Geng, Torén \& Salomon, 2009; Gudmundsson \&Tómasson, 2009; lanbukhtina, Masiagutova \& Gainullina, 2011; Kirychuk et al., 1999; Martinez, Gratton, Coggin, René \& Waller, 2004; Mitloehner \& Calvo, 2008; Receveur, 2005; Safin, Masiagutova, Khusnarizanova \& lanbukhtina, 2009; Von Essen \& Donham, 1999). Da mesma forma, são raros os estudos sobre as vivências subjetivas de trabalhadores inseridos em cooperativas rurais, ou mesmo, sobre o papel destas organizações no processo de saúde e de adoecimento dos cooperados.

Uma revisão sistemática realizada nas bases LILACS, Index Psi, PePSIC, SciELO e Biblioteca Cochrane, considerando o período de junho de 1999 a junho de 2013 e utilizando o descritor "cooperativismo", identificou 102 documentos. Deste total, apenas 16 estudos estavam relacionados ao cooperativismo no meio rural; a grande maioria (13) teve como objetivo investigar aspectos da administração financeira, falência, estratégias de crescimento e capital das cooperativas, um artigo teórico discutiu o cooperativismo no contexto do Movimento dos Trabalhadores Sem Terra (MST), e dois eram estudos de caso de cooperativas rurais, detendo-se ao relato de experiência das organizações quanto à gestão participativa e ao modelo de governança. Não foram identificados estudos acerca das vivências de trabalho, saúde ou adoecimento de trabalhadores inseridos em cooperativas rurais.

Sabe-se que a Organização do Trabalho (OT) é considerada determinante nas manifestações do processo saúde/doença dos trabalhadores, deste modo, analisar a OT cooperado e o reflexo de suas características na saúde mental do trabalhador é de fundamental importância para o desenvolvimento de ações capazes de intervir nas situações que estejam gerando danos aos profissionais (Dejours, 1992; Heloani \& Lancman, 2004; Mendes, 2007a). O conceito de OT está atrelado aos aspectos da divisão do trabalho e da divisão dos homens. A primeira está relacionada ao escopo de atuação dos trabalhadores, ao modo como as atividades são organizadas, ao ritmo, à repartição e às prescrições de modo geral. Já a segunda é composta pelas características de gestão que atuam na codificação e definição das relações de trabalho, tais como: controles existentes, hierarquia, grau de autonomia, possibilidades de cooperação e comunicação, relações de poder e comando de modo geral (Dejours \& Abdoucheli, 2011).

O sofrimento, considerado inerente ao trabalho, se intensifica quando a negociação entre o sujeito e a realidade apresentada pela OT deixa de existir. Além disso, fatores como a precarização da OT, a necessidade de sobrevivência e a desestruturação do coletivo vulnerabilizam o trabalhador frente ao sofrimento e podem direcioná-lo para o desenvolvimento de estratégias defensivas mais pautadas na fuga ou negação do sofrimento, do que na mobilização para transformação da OT. Funcionamento que, se prolongado por muito tempo, pode desencadear patologias do trabalho (Mendes, 2007a). Por outro lado, o prazer proveniente do trabalho se estabelece através da mobilização subjetiva, quando há espaço para que o trabalhador possa enfrentar ou transformar as imposições e pressões estabelecidas pelo trabalho, se sentindo reconhecido por fazer uso de sua inteligência e subjetividade (Mendes, 2007a).

Tendo em vista os pressupostos e também as lacunas teóricas aqui apresentadas, este estudo teve como objetivo principal analisar as vivências de prazer e sofrimento de suinocultores frente ao modelo de trabalho cooperado e, como objetivos específicos, caracterizar o trabalho cooperado na suinocultura e compreender as estratégias defensivas utilizadas pelos trabalhadores para lidar com o sofrimento. A contribuição desta investigação está pautada na possibilidade de tornar conhecidas as vivências 
destes trabalhadores com relação ao trabalho cooperado, possibilitando reflexões acerca dos efeitos deste modelo na saúde mental dos suinocultores e no quanto ele contribui, de fato, para a emancipação ou para a precarização do trabalho na suinocultura.

\section{Método}

Esta pesquisa foi desenvolvida conforme o método exploratório descritivo, a partir de uma perspectiva qualitativa, capaz de permitir que a singularidade de cada sujeito seja considerada no processo de construção do conhecimento (Rey, 2005).

\section{Contexto de pesquisa e participantes}

Este estudo contou com a participação de 16 suinocultores, oito homens e oito mulheres, com idade entre 19 e 67 anos (M: 45,8; DP: 13), todos casados, sendo que dois não tinham filhos. Nove participantes tinham ensino fundamental incompleto, seis completo e um possuía o ensino médio completo. Dois participantes se declararam terceiros e todos os outros eram proprietários do negócio. Os suinocultores estavam vinculados a uma cooperativa regional e residiam em uma comunidade rural do oeste de Santa Catarina. Na região, a suinocultura possui forte importância econômica e, somente no estado, conta com cerca de 12.000 suinocultores, empregando diretamente 65.000 pessoas e, indiretamente, mais de 140.000. O estado é responsável por $25 \%$ da produção nacional de carne suína e, na região oeste concentram-se $70 \%$ de todo rebanho de Santa Catarina (Associação Catarinense de Criadores Suínos, 2008).

Os trabalhadores cuidavam de 330 a 1025 suínos (M: 540,6; DP: 211) e o tempo de atuação na suinocultura variou de dois anos e cinco meses a 45 anos (M: 17,8; DP: 17). Os trabalhadores realizavam a etapa produtiva da suinocultura denominada terminação, na qual ocorre a engorda dos suínos para posterior abate. Quanto à renda familiar mensal, 11 participantes declararam receber entre um e dois salários mínimos e os outros cinco participantes, três salários mínimos.
Os critérios de inclusão deste estudo foram: suinocultores proprietários ou terceiros; que estivessem na atividade há pelo menos dois anos; que declarassem como atividade principal a suinocultura; maiores de 18 anos; que poderiam realizar outras atividades rurais além da suinocultura; e poderiam ser familiares. O critério de exclusão estabelecido foi o de que proprietários e terceiros de uma mesma propriedade não poderiam participar do mesmo grupo focal, impedindo possíveis constrangimentos nos relatos quanto aos aspectos relacionados ao trabalho. Com o intuito de facilitar a análise dos dados e preservar a identidade dos participantes, os nomes dos suinocultores do primeiro grupo foram substituídos por Ana, Maria, Clara, Paulo, André, Lucas, Laura e João, e os nomes dos participantes do segundo grupo foram substituídos por Lurdes, Márcia, Pedro, Marcelo, Luiz, Paula, Ricardo e Sônia. Da mesma forma, a cooperativa na qual os participantes estavam vinculados foi chamada de Cooperativa 1 e a empresa processadora de alimentos recebeu o nome de Empresa X.

Técnicas e instrumento de coleta de dados

Foram utilizados, respectivamente, como técnica e como instrumento de pesquisa: grupos focais, observações de campo e questionário biossociodemográfico. A técnica de grupo focal privilegia o aspecto interativo da coleta de dados, possibilitando a produção de dados e insights (Morgan, 1997). O número de participantes foi definido de acordo com as indicações de Morgan (1997) e a condução das discussões foi feita através de um roteiro adaptado, a partir do modelo apresentado por Mendes (2007b). O roteiro foi composto por temas como: organização do trabalho; vivências de sofrimento; estratégias defensivas utilizadas e possibilidades de transformação da organização do trabalho.

Buscando identificar as características dos participantes e levantar informações sobre o trabalho, foi construído, para este estudo, um questionário biosociodemográfico. E com o objetivo de aproximar o pesquisador da realidade vivenciada pelos trabalhadores, foi utilizada a técnica de observador-como-participante, na 
qual o pesquisador se identifica como tal e realiza observações livres durante breves períodos (Angrosino, 2009). Os dados provenientes das observações foram registrados em diário de campo.

\section{Procedimentos éticos e de pesquisa}

Este estudo seguiu as diretrizes da Resolução $n^{\circ}$ 016/2000, do Conselho Federal de Psicologia (2000), bem como da Resolução no 196/96, do Conselho Nacional de Saúde (Brasil, 1996), e foi aprovado pelo Comitê de Ética em Pesquisa da Universidade Unisinos, número 12/132. Após a aprovação do projeto teve início a seleção dos participantes através da metodologia snowball ou "Bola de Neve" (Biernacki \&Waldorf, 1981). Primeiramente houve a aproximação do pesquisador com o campo investigado, para posterior identificação de alguns suinocultores e visitas às residências dos indicados para a formalização dos convites para participação da pesquisa. Antes do início da coleta, foi realizado um estudo piloto dos roteiros utilizado nos grupos focais e do questionário, resultando em pequenos ajustes.

Os grupos focais foram realizados na própria comunidade dos participantes e organizados em dois encontros, sendo que cada grupo contou com a participação de oito trabalhadores. Os grupos foram filmados em vídeo e áudio e conduzidos por uma moderadora e por uma comoderadora. No primeiro encontro foram entregues os Termos de Consentimento Livre e Esclarecido e o questionário para ser preenchido pelos próprios participantes. Para a condução do grupo focal foi utilizado o roteiro já referido. No segundo encontro foi realizada a validação dos dados obtidos, além de discussões acerca das possibilidades de melhorias no trabalho dos participantes.

Durante a permanência do pesquisador no campo investigado foram acompanhadas as atividades de nove trabalhadores, totalizando 15 horas de observação livre. A coleta de dados foi efetivada nos meses de janeiro e fevereiro de 2013, e seis meses depois foi realizada a devolução dos resultados do estudo aos suinocultores e à Cooperativa 1 .

Procedimentos de análise dos dados

Os dados gerados, com base nos grupos focais, foram transcritos na íntegra e analisados através de análise de conteúdo (Bardin, 1977). A análise de dados empregada permitiu a extração de três categorias definidas a priori: caracterização do modelo de trabalho cooperado na suinocultura; vivências de sofrimento no trabalho cooperado; e estratégias defensivas frente ao sofrimento. Enquanto que, a posteriori, foi identificada a categoria ensaios para a transformação da realidade vivenciada. As informações coletadas através do questionário foram analisadas de maneira descritiva e os registros em diário de campo foram utilizados para a descrição do modelo de trabalho cooperado na suinocultura.

\section{Resultados e Discussão}

\section{Caracterização do modelo de trabalho cooperado na suinocultura}

O trabalho dos participantes deste estudo é organizado e gerido por uma grande empresa processadora de alimentos (Empresa X), constituída por inúmeras cooperativas que possuem o papel de intermediar a relação de trabalho com os suinocultores e de comercializar os suínos produzidos. Nesta dinâmica, os suinocultores oferecem a infraestrutura necessária para o recebimento dos suínos e a mão de obra, sem nenhuma relação formal de trabalho com a Cooperativa 1 , à qual são vinculados.

A Cooperativa 1 dispõe aos produtores suporte técnico, alimentação para os suínos, medicação e insumos em geral, que são descontados ao final do ciclo produtivo, quando os suínos são comprados, abatidos e comercializados pela Empresa X. Além de cooperado, o suinocultor é cliente dos diversos estabelecimentos comerciais e industriais da Cooperativa 1. Com isso, muitas vezes, o lucro obtido na venda dos suínos retorna totalmente para a cooperativa, efetivando o 
pagamento das dívidas geradas pelas compras de supermercado, combustível e ferramentas.

Os suinocultores recebem o pagamento pelo trabalho realizado a cada quatro meses, o que corresponde a um ciclo produtivo. $\mathrm{O}$ resultado financeiro está atrelado aos indicadores de qualidade e de produtividade, tais como: conversão alimentar (quantidade de ração versus o peso dos suínos), taxa de mortalidade e peso da carcaça do animal. O valor final de cada suíno, considerando os descontos dos insumos fornecidos, pode variar de 8,00 a 24,00 reais, sendo que cada animal entregue pesa em média $120 \mathrm{~kg}$. No caso dos trabalhadores terceiros, o proprietário das pocilgas repassa um percentual do lucro obtido com a venda dos suínos.

Vivências de sofrimento no trabalho cooperado

Crescimento da cooperativa através da exploração do trabalhador

Apesar de se tratar de uma cooperativa que legalmente deveria constituir-se como um espaço de emancipação dos trabalhadores através da prática da autogestão, da garantia dos direitos sociais, da livre iniciativa e, principalmente, da não precarização do trabalho [Lei no 12.690/2012 (Brasil, 2012)], o modelo de gestão vivenciado pelos suinocultores em nada se difere daquele praticado por grandes empresas orientadas para o mercado (Lima, 2009). Na perspectiva dos participantes, a cooperativa possui um ideal de lucro e tem crescido consideravelmente nos últimos anos, enquanto eles têm presenciado a redução gradativa dos valores recebidos e o aumento das exigências de produtividade. Algumas falas demonstram este achado:

"Mas, na minha opinião, a cooperativa só ganha, eles vivem gastando dinheiro, fazendo prêmios, festas, crescendo e nós só ganhamo menos. Eles tiram muito dinheiro de nós" (Pedro); "Eles tão reduzindo a conversão, mudaram a tabela, a gente precisa tratar menos e os porco têm que pesar mais" (Laura).

Os suinocultores salientaram que nos últimos anos houve um aumento dos controles de qualidade e os processos produtivos tornaram-se mais rígidos, gerando mudanças constantes nas normas de trabalho, além de burocracia e prejuízos financeiros, conforme relatos:

"É tudo determinado pelos técnico. É, tu tem que seguir as quantidades de ração, as medicação" (André).

Na visão desses trabalhadores, os padrões de qualidade agem de maneira contraditória, reduzindo os bons resultados gerados pelo trabalho. Neste cenário, a inteligência prática do suinocultor é totalmente desconsiderada pelas normas e procedimentos de trabalho, dificultando que o saber construído seja utilizado para a realização das atividades.

Os participantes também trouxeram a percepção de que a preocupação e a fiscalização com relação às normas de qualidade são aplicadas apenas para eles, visto que constantemente recebem suínos em condições impróprias, o que acaba prejudicando o resultado do trabalho. Alguns relatos ilustram esta vivência:

"[...] lá em casa, eu recebi já um leitão de catorze quilo, na nota dizia que ele tinha dezenove, mas ele tinha catorze, nós pesamo. Depois, ainda tiveram coragem de dizer que o problema foi que nossa balança tava errada" (Luiz).

Além disso, foi mencionado que os técnicos, responsáveis pela fiscalização dos itens de qualidade no trabalho, falsificam registros de visitas e acompanhamentos:

\section{"No último lote, ele marcou umas visi- tas a mais que ele não foi... Mas ele não fez essas visitas. E não é só lá em casa" (Luiz).}

Quando questionados sobre o motivo pelo qual a cooperativa realizava esta prática de gestão, pautada na intensificação dos controles de qualidade e no aumento das exigências de produtividade, os suinocultores trouxeram o discurso de que a instituição também é vítima do sistema político e 
econômico vigente, e que cobra porque também é cobrada:

"Isso vem de cima né, os país que com-
pram as carne exigem esses controles de
qualidade. Eles que fiscalizam a gente,
também são mandado, tem que fazer
o que vem de cima. Vai apertando pra
baixo e chegando na gente" (Lucas).

Com isso, surgem sentimentos de solidão e impotência diante dos fatores geradores de sofrimento:

"A Empresa X só cresce, está se tornando única aqui na região, comprou várias outras empresas, só cresce. Não temo o que fazê, somo fraco demais. E a gente se fosse unido, também podia conseguir as coisas, nós sozinho não vencemo eles que são grande demais" (João).

Estas vivências remetem aos impactos gerados pelo modo de acumulação flexível de capital, pautado no individualismo e na intensificação do trabalho, que tem sido fonte inesgotável de sofrimento e solidão, contribuindo consideravelmente para $\mathrm{o}$ aumento das patologias relacionadas ao trabalho (Dejours \& Bègue, 2010).

Através destes dados, percebe-se que o crescimento econômico da Cooperativa 1 não está atrelado às melhorias nas condições de trabalho e na qualidade de vida dos suinocultores, gerando uma dissociação entre expansão do lucro e desenvolvimento social (Sabroza, Leal \& Buss, 1992). Corroboram estes resultados, estudos anteriores acerca do agronegócio no meio rural, que demonstraram que o modelo vigente de desenvolvimento econômico da agricultura brasileira, além de causar grandes transformações nos territórios, transforma o modo de vida e o cenário de saúde, constituindo um espaço desprovido de condições dignas de trabalho que impactam diretamente na qualidade de vida do trabalhador rural (Pessoa \& Rogotto, 2012). Além disso, o cooperativismo que poderia apoiar na transformação deste cenário e no empoderamento dos trabalhadores atua como ferramenta de submissão, exploração e intensificação do sofrimento dos suinocultores.
Sistema de pagamento: "uma caixa de surpresa"

Uma das dimensões do trabalho precarizado é a fragilização do vínculo trabalhista e da relação contratual, caracterizada pela perda dos direitos do trabalhador, como por exemplo, reduções salariais, ausência de benefícios diretos e indiretos, entre outros. Estas perdas levam à desestabilização e à ausência dos referenciais de proteção social, gerando insegurança, competitividade e instabilidade, condições que abrem espaço para a gestão pelo medo (Franco, Druck \& Seligmann-Silva, 2010). Esta importante dimensão do trabalho precário é considerada pelos suinocultores uma das principais fontes de sofrimento, na medida em que impacta e altera a vida dentro e fora do trabalho.

Os trabalhadores, de modo geral, não entendem como são calculados os valores que compõe o pagamento, o que gera a sensação de que não estão recebendo corretamente:

"Uma veiz nós tinha um lote que o téc-
nico falou que se os porco pesassem
cento e dezenove quilo ia dar bom o
lote, porque ele já tava comparando
com o que os porco tinham comido.
Deu cento e vinte e quatro quilo e em
dinheiro deu péssimo, até hoje eu não
entendo o que deu ali" (Ana).

A falta de previsão do valor que será recebido ao final dos quatro meses do ciclo produtivo provoca insegurança:

"Tipo assim, é muita indiferença. Às
veiz tu manda um lote que tu acha que
vai bem e acaba indo mal, ou tu manda
um lote que tem tudo pra ir mal e vai
bem. Tem muita diferença assim, tu não
sabe o que esperar. Tu não sabe se vai
dar bem ou mal [...] Eu me sinto muito
inseguro com isso, não sei o que esperá
do futuro" (Luiz); "Realmente, é uma
caixa de surpresa" (Ricardo).

Quando questionados sobre o que faziam diante da incerteza do pagamento ou da não concordância sobre os valores pagos, os trabalhadores mostraram pouca condição de questionamento e mobilização: 
"Tu vai fazer o quê? Tu tem que pegar aquilo ali e aceitar o que eles disseram" (Lucas).

Este cenário parece se agravar com os trabalhadores terceirizados, visto que não realizam atividades alternativas na agricultura e dependem unicamente do resultado proveniente da suinocultura:

"E nóis que trabalhamo pros outros, só temos aquele salário pra viver, se der mal, a gente fica sem dinheiro. Dá uma miséria [...] Cada lote que dá mal eu entro em desespero. Tu fica ali quatro mêis trabalhando e no final não dá quase nada, é muito triste. Final de semana direto ali, feriado, tudo... E chega no final não dá nada. Quem não fica desesperado?" (Maria).

Desta forma, pode-se perceber que, se por um lado a realização de atividades rurais alternativas aumenta a sobrecarga de trabalho acarretando falta de tempo para descanso e inúmeros efeitos sobre a saúde do trabalhador, por outro lado, atenua a insegurança e os prejuízos gerados pela instabilidade do pagamento na suinocultura, representando outra fonte de renda.

No caso dos proprietários, um fator agravante é que para a construção das pocilgas são realizados longos financiamentos, sendo parte do resultado financeiro obtido com os suínos, destinado para o pagamento destes valores. Desta forma, o recebimento de valores variáveis ou mesmo de resultados pouco satisfatórios, implica diretamente no adiamento ou no não pagamento das parcelas dos empréstimos realizados. Esta situação pode ser identificada nas falas:

"Tu fica véinho e ainda tá pagando [...] É sofrido" (João); "E tu pode ver, se tem uma coisa mais importante assim, que nem os financiamento, tu não consegue dormir, outra noite eu me acordei cinco veiz. É uma coisa que tu dorme mal. Cinco veiz. É demais acordado" (Ana).

De acordo com Silva (2007, p. 116), o endividamento atua como um "banalizar das relações sociais", sendo que na condição de endividado, o trabalhador passa a sofrer críticas dos familiares, amigos, vizinhos e da própria sociedade, podendo ser considerado preguiçoso ou sem credibilidade. Não bastassem os impactos subjetivos e sociais do endividamento, a literatura mostra que as preocupações com as dívidas geram nos trabalhadores rurais, além de dificuldades para dormir, sintomas de ansiedade e depressão mais elevados, em comparação com aqueles detentores de trabalho fixo (Lima, Rossini \& Reimão, 2010).

Além disso, tanto os trabalhadores proprietários das pocilgas, quanto os terceiros, relataram sentimentos de desespero diante da morte dos suínos, visto que cada perda reflete diretamente nos resultados financeiros. Este sofrimento parece se agravar quando as mortes ocorrem alguns dias antes da entrega dos suínos:

"Tem vez que dá um estressamento, um
desespero mesmo [...] Porque a pessoa
tá cuidando ali, todo dia, daí dá uma
doença os porco adoecem, morrem...
Quando tão já quase pronto. Que nem
já aconteceu... [...] Daí dá um estresse.
Tava tudo certo pra dá um lote bão, e daí
eles começam morrê, um, dois por dia. A
gente cuida, trabalha e só perde" (Sônia).

A falta de apoio e suporte técnico por parte da Cooperativa 1, intensiva o sofrimento:

"[...] eu falei com o técnico na segunda e ele veio só na quinta, daí já tinha morrido um monte [...] Depois que os porco já tinham morrido veio o técnico com um remédio pra água, mas daí já era tarde" (Paulo); "Lá em casa deu diarreia nos porco no final de semana, eu tentei ligar pros técnicos, tentei e ninguém atendia nada... foi um desespero, nós via eles morrendo e não tinha o que fazê" (João).

Os relatos apresentados apontam para uma enorme vulnerabilidade dos suinocultores, desprovidos de apoio, totalmente submissos às políticas de mercado e ao modelo de gestão praticado pela Cooperativa 1. A situação de trabalho extremamente precária só não é pior porque os trabalhadores fazem uso da terra para cultivar produtos que subsidiam a 
alimentação familiar, caso contrário, teriam de enfrentar, inclusive, a fome.

Diante do perverso modelo de remuneração, da exploração, da falta de apoio social e da consequente ausência de um coletivo de trabalho, o sofrimento silenciado e sem espaço para transformar a OT produz efeitos negativos na saúde mental dos trabalhadores, gerando insegurança com relação ao futuro, tristeza, desânimo, sentimento de impotência, desesperança e solidão. Neste sentido, se o foco da clínica do trabalho são os destinos do sofrimento (Périlleux, 2013) e se estes destinos indicarão se ele atuará como mediador da saúde ou do adoecimento (Dejours, 2004; 2008), as vivências de trabalho dos suinocultores frente ao modelo de trabalho cooperado apontam para um cenário marcado muito mais pelo sofrimento patogênico e submissão, do que pela saúde e emancipação dos trabalhadores.

Relação de trabalho: onde cooperados se sentem peões

Na perspectiva dos suinocultores, a relação de trabalho que possuem com a cooperativa faz com que se sintam peões, como expressado por Marcelo:

"Ali dentro da cooperativa nós somo pião. Tem que fazer como eles mandam. Na verdade a gente é empregado deles, tem que fazer como eles mandem, não tem jeito. Mesmo que a gente não concorde" (Marcelo).

O significado de serem peões remete a uma conotação de humilhação e de falta de valor, atrelados, especialmente, à ausência de espaços de fala, de escuta e de participação nas decisões relacionadas ao trabalho. Estudos anteriores da psicodinâmica do trabalho mostram que os espaços de discussões existentes na organização do trabalho possuem um papel fundamental na ressignificação do sofrimento em busca do prazer, na construção da mobilização coletiva e na promoção da saúde mental do trabalhador (Bottega \& Merlo, 2010; Carvalho \& Morares, 2011; Mendes \& Facas, 2011). Quando, ao contrário, o sofrimento não pode ser expresso e compartilhado, a impotência assume o lugar da politização (Périlleux, 2013).

O principal canal de comunicação que os suinocultores possuem para expor as críticas ou sugestões inerentes ao trabalho é através do técnico que acompanha as atividades realizadas junto aos suínos, no entanto, algumas falas demonstram que este canal é frágil e que não possui potencial para dar voz aos trabalhadores:

"Eu falei com o técnico, ah... mas eles sempre têm alguma explicação, alguma coisa pra dizer [...]" (Lurdes).

Um segundo canal de comunicação com a cooperativa eram as assembleias, reuniões ou mesmo capacitações ocorridas. No entanto, os trabalhadores mencionaram que estes momentos deixaram de acontecer há mais de dois anos, e que, mesmo quando ocorriam, não havia espaço para participação coletiva:

"Quando eles abriam espaço, eles dei-
xavam perguntá só sobre o assunto que
eles tavam falando, não dá pra nós fala
o que quisemo" (Luiz).

Diante do questionamento sobre porque não se organizavam para expor esta problemática, o medo apareceu como principal impedimento:

"Depois eles perseguem a gente" (João); "Eles podem prejudicar, tocar pra cima" (Ricardo).

Os relatos das vivências destes trabalhadores corroboram os dados de um estudo realizado por Oliveira (2007) com integrantes de uma cooperativa de mão de obra na área da saúde. A investigação mostrou que o trabalho cooperado neste meio era de caráter tradicional, no qual a cooperativa existia para permitir a contratação flexível de mão de obra com menor custo, sem incluir em seus objetivos a tentativa de mudar a forma de gestão ou de transferir o controle do negócio aos trabalhadores. Da mesma forma, as falas dos suinocultores acerca da relação de trabalho que possuem com a cooperativa contradizem os aspectos legais instituídos para o estabelecimento do cooperativismo. 
O cenário vivenciado aponta muito mais para uma relação de exploração da mão de obra do que para uma perspectiva de trabalho cooperado, descrito por Lima (2009) como um trabalho autônomo, coletivamente gerido e ideologicamente orientado para fora do mercado. Diante disso, cabe fazer uso das palavras de Oliveira (2007, p. 81 ) que, ao discutir o modelo de trabalho cooperado, traz a perspectiva de que se as relações de trabalho existentes no cooperativismo não diferem daquelas estabelecidas pelas empresas convencionais, "significa que a experiência do cooperativismo de mão de obra não representa transformação das relações de trabalho vigentes, mas o aprofundamento da precarização do trabalho".

\section{Estratégias defensivas frente aos fatores sofrimento}

Submissão: "Se pudé engoli, engole, se não, toma uma água que desce"

As estratégias defensivas, fundamentadas na negação, atuam de maneira ambivalente, protegendo o trabalhador do sofrimento, mas também impedindo que os fatores geradores de sofrimento sejam transformados (Dejours, 2004; Moraes, 2013). Neste estudo, os trabalhadores relataram que não costumam questionar as diretrizes e o funcionamento da cooperativa por medo de serem substituídos, perdendo assim a principal fonte de renda:

"Eu acho que é assim mesmo, porque se você ficar brigando, quando vê eles fecham o chiqueiro da gente. Tem outros que querem" (Luiz); "É... mesmo a gente não concordando, tem que fazer como eles mandam. Mesmo que a gente acha que as coisas tão errada tem que fazer, né..." (Lucas).

Frente às ameaças do desemprego, os trabalhadores têm o medo reforçado, o que acaba contribuindo para a submissão. $\mathrm{O}$ temor pessoal individualiza o sofrimento daqueles que estão nessa condição e atua como desmobilizador do coletivo de trabalho (Dejours, 2001).

Diante do medo e da impossibilidade estabelecida, ora pelas ameaças da cooperativa, ora pela ausência de mobilização coletiva, os trabalhadores acabam buscando formas de adaptar suas necessidades às da OT:

"É. Tem coisa que a gente vai deixando, deixando e fica... se torna esquecido, a gente se acostuma" (Ricardo);

"[...] No fundo, a gente tava certo. Na verdade, quando eles vão visitar e tem uma coisa errada, eles não perdoam, então, se nós tava certo, nós também tinha o direito de reclamá. Mas daí a gente não foi atrás, deixamo por isso mesmo" (Lucas).

Através da adaptação, surge a esperança de que a situação ou as dificuldades vivenciadas irão melhorar. Neste caso, a esperança apareceu mais como uma espera passiva de que algo mude sem que nada seja feito do que propriamente um motivador para a transformação dos fatores de sofrimento: "

Quando tu vai mal num lote, tu espera que o outro seja melhor, né, mas daí vem o outro e vai mal de novo, daí tu torce pro outro e assim vai..." (André).

Nos momentos em que esta espera se torna insustentável, surgem reações como o choro e o desejo de deixar a atividade:

"Eu choro, quero ir embora [...] Daí passa" (Clara); "Sempre passa de novo" (Ana).

Induzidos a não contestação das condições às quais estão submetidos, estes trabalhadores acabam por alimentar a própria submissão. Percebe-se que a negação dos direitos e a subestimação do saber dos suinocultores estão relacionadas à desigualdade social a qual estão submetidos, à baixa renda, à falta de alternativas diferenciadas de emprego, à cultura de dominação, dentre outros fatores que contribuem para uma maior vulnerabilidade dos trabalhadores (Alexandre, 2009).

\section{Individualismo}

Apesar da organização do trabalho na suinocultura estar baseada no cooperativismo, os participantes relataram atitudes individualistas e competitivas na relação com seus pares. Estas podem ser observadas através do receio 
de que outros suinocultores descubram as técnicas utilizadas para obtenção de resultados financeiros satisfatórios e da falta de comunicação e cooperação entre os pares:

"Eu não acho certo isso, porque eu tenho que ajudar o outro se o outro fez errado e eu fiz tudo certo? É o meu suor que tá lá..." (Lucas).

O individualismo é utilizado pela organização do trabalho e atua contra os próprios trabaIhadores, na medida em que impossibilita a mobilização coletiva, a troca de experiências e a comunicação. Desta forma, evidencia-se um aspecto já discutido por Dejours (2008) e Mendes (2007a), de que a OT não explora o sofrimento em si, mas sim as estratégias defensivas utilizadas pelos trabalhadores para lidarem com o sofrimento, pois, na medida em que os suinocultores se submetem à OT de maneira individualizada, são mais facilmente manipulados e direcionados a agir de acordo com os pressupostos da Cooperativa 1.

Sendo assim, entende-se que a fragilização do coletivo de trabalho e o individualismo intensificam a exploração, o sofrimento e a precarização. Caso esta estratégia de defesa fosse transformada, os próprios trabalhadores poderiam compartilhar melhores práticas de trabalho para alavancar o negócio dos seus pares e/ou se mobilizar para compartilhar as dificuldades, possibilitando a transformação dos fatores geradores de sofrimento provenientes da OT. No entanto, o que se destaca é o uso maciço de estratégias defensivas individuais, conduzindo os trabalhadores para o esgotamento de suas potencialidades e para o estado de solidão, desespero e tristeza.

Ensaios para a transformação da realidade vivenciada

Sabe-se que mesmo contextos de atuação profissional precarizados podem proporcionar prazer ao trabalhador, desde que haja espaço para a cooperação, para a fala, para a mobilização da inteligência e dos conhecimentos construídos pelo trabalhador em seu cotidiano de trabalho (Mendes, 2007b). Quando no segundo encontro os participantes foram instigados a pensar e a propor sugestões de melhorias para as suas condições de trabalho, houve sinalizações de diversas possibilidades de transformação da realidade vivenciada, pautadas em três esferas principais: possibilidades de mobilização coletiva, melhorias nas condições de trabalho e sugestões para práticas governamentais.

Um aspecto que teve grande contribuição para os efeitos emancipatórios da pesquisa foi a validação dos dados nos grupos focais, bem como a devolução final do estudo para os participantes e para a Cooperativa 1 . Percebeu-se que estas etapas serviram não apenas como instrumento metodológico, mas também como um recurso no qual os próprios trabalhadores puderam escutar, refletir e ressignificar suas falas. Após as devoluções, os participantes realizaram um jantar para continuar as discussões sobre as melhorias nas condições de trabalho e a Cooperativa 1 organizou um ciclo de reuniões com todos os suinocultores da região para levantar sugestões acerca do funcionamento do trabalho cooperado.

Deste modo, entende-se que um caminho possível para transformar a realidade vivenciada é tornar claro e conhecido para os próprios trabalhadores os fatores de sofrimento e as precárias condições de trabalho às quais estão submetidos. Através da percepção e ressignificação da realidade, conseguirão também se sensibilizar com o sofrimento de seus pares, diminuindo o individualismo e buscando alternativas conjuntas para o fortalecimento de suas identidades e cidadania.

\section{Conclusões}

Este estudo buscou analisar as vivências de prazer e sofrimento de suinocultores frente ao modelo de trabalho cooperado na suinocultura ao problematizar o papel do cooperativismo na precarização ou na emancipação dos trabalhadores. Os resultados enfatizaram as vivências de sofrimento dos participantes, atreladas, principalmente, a aspectos da OT cooperado que é caracterizada pelo crescimento da cooperativa através da exploração dos trabalhadores, 
pela falta de autonomia e de participação dos cooperados, pela rigidez dos processos de trabalho, pela falta de espaços de fala e escuta, e principalmente, pelo precário modelo de remuneração praticado. Diante do sofrimento, os trabalhadores fazem uso de estratégias defensivas pautadas na submissão e no individualismo, reforçadas pelo medo e ameaças praticadas pela cooperativa. Situação que culmina nos sentimentos de solidão, desesperança e insegurança frente ao futuro, dificultando a cooperação e a mobilização coletiva diante dos fatores geradores de sofrimento. Nesta dinâmica, os participantes não sinalizaram vivências de prazer frente ao modelo de trabalho cooperado, mas conseguiram pensar ao longo dos grupos focais em possíveis iniciativas na busca por melhorias das condições de trabalho.

As análises realizadas identificaram elementos suficientes para concluir que o trabalho cooperado para os suinocultores investigados tem atuado muito mais na intensificação da precarização do que, de fato, na emancipação dos trabalhadores. Além disso, foi possível identificar impactos deste modelo na saúde mental do suinocultor, como por exemplo, os sentimentos de solidão, insegurança, tristeza e desespero, presentes em diversos relatos. Estes efeitos se mostraram atrelados à incerteza do pagamento, aos mecanismos de submissão à organização do trabalho que impedem a mobilização coletiva e intensificam a experiência de sofrimento, além da baixa participação dos suinocultores nos modos de fazer do trabalho, reduzindo os espaços de prazer e de realização no trabalho.

Como limitação do estudo pode ser citado o número de encontros reduzidos dos grupos, o que pode ter restringido algumas colocações. Caso os encontros fossem estendidos, possivelmente os efeitos positivos da pesquisa aos suinocultores seriam ampliados, em função do espaço público de fala e escuta. Quanto às sugestões para futuros estudos, foi identificada a necessidade de levantamentos acerca do estado de saúde mental dos trabalhadores rurais, pois são raros os estudos com este objetivo, e os existentes encontram-se desatualizados. Sugere-se também, que sejam ampliadas as investigações sobre as configurações do trabalho rural, especialmente acerca dos modelos de cooperativismo e seus efeitos na saúde do trabalhador, possibilitando atribuir maior visibilidade a este cenário, e quem sabe, contribuir para a melhoria das condições de vida e trabalho desta população. 
Referências
Alexandre, S. F. (2009). Estudo dos agravos à saúde dos trabalhadores expostos a agrotóxicos no agronegócio do abacaxi em Limoeiro do Norte - Ceará. Dissertação de mestrado, Universidade Federal do Ceará, Fortaleza, CE.

Angrosino, M. (2009). Etnografia e observação participante. Porto Alegres, RS: Artmed.

Associação Catarinense de Criadores de Suínos (2008). Histórico da suinocultura. Recuperado em 14 de maio de 2012, de http://www.accs.org.br/arquivos_internos/ index.php?abrir=historico_agroindustrias

Bardin, L. (1977). Análise de conteúdo. (L. Reto, \& A. Pinheiro, trad.) São Paulo, SP: Edições 70.

Biernacki, P.; \& Waldorf, D. (1981). Snowball sampling: problems and techniques of chain referral sampling. Sociological Methods \& Research, 10(2), 14-38.

Bottega, C. G., \& Merlo, A. R. C.. (2010). Prazer e sofrimento no trabalho dos educadores sociais com adolescentes em situação de rua. Cadernos de Psicologia Social do Trabalho, 13(2), 259-275.

Brasil. (1971). Lei $n^{\circ} 5.764$, de 16 de dezembro de 1971. Define a Política Nacional de Cooperativismo, institui o regime jurídico das sociedades cooperativas, e dá outras providências. Recuperado de http://www. planalto.gov.br/ccivil_03/leis/l5764.htm

(2012a). Lei $n^{\circ}$ 12.690, de 19 de julho de 2012. Dispõe sobre a organização e o funcionamento das Cooperativas de Trabalho; institui o Programa Nacional de Fomento às Cooperativas de Trabalho PRONACOOP; e revoga o parágrafo único do art. 442 da Consolidação das Leis do Trabalho - CLT, aprovada pelo Decreto-Lei no 5.452, de 10 de maio de 1943. Recuperado de: http://www.planalto.gov.br/ccivil_03/_ Ato2011-2014/2012/Lei/L12690.htm

(1996). Ministério da Saúde. Resolução $n^{\circ}$ 196/96. Diretrizes e normas regulamentadoras de pesquisas envolvendo seres humanos. Brasília, DF: Ministério da Saúde.

(2012b). Ministério da Agricultura. Suínos. Recuperado de http://www. agricultura.gov.br/animal/especies/suinos
Carelli, R. L. (2002). Cooperativas de mão de obra: manual contra a fraude. São Paulo, SP: LTR.

Carvalho, G. M., \& Moraes, R. D. (2011). Sobrecarga de trabalho e adoecimento no Pólo Industrial de Manaus. Psicologia em Revista, 17(3), 465-482.

CentraldelnteligênciadeAveseSuínos [CIAS].(2012). Distribuição espacial da produção de suínos no Brasil. Recuperado de http://www.cnpsa. embrapa.br/cias/index.php?option $=$ com content\&view $=$ article\&id $=59$

Cole, D. J., Hill, V. R., Humenik, F. J., \& Sobsey, M. D. (1999). Health, safety, and environmental concerns of farm animal waste. Occupational Medicine, 14(2), 423-48.

Conselho Federal de Psicologia [CFP]. (2000). Resolução 016/2000. Resolução para pesquisa com seres humanos., Brasília, DF: CFP. Recuperado de: http://pol.org.br/ legislacao/pdf/resolucao2000_3.pdf

Dejours, C. (2008). A avaliação do trabalho submetida à prova do real. São Paulo, SP: Blucher.

(2001). A banalização da injustiça social (4a ed.). Rio de Janeiro, RJ: FGV.

Dejours, C. (1992). A loucura do trabalho: estudo de psicopatologia do trabalho (5a ed.). São Paulo, SP: Cortez.

(2004). Da psicopatologia à psicodinâmica do trabalho. Rio de Janeiro, RJ: Editora Fiocruz.

Dejours, C., \& Abdoucheli, E. (2011). Itinerário teórico em psicopatologia do trabalho. In C. Dejours, E. Abdoucheli, \& C. Jayet, Psicodinâmica do trabalho: contribuições da escola dejouriana à análise da relação prazer, sofrimento e trabalho (p. 119-145). São Paulo, SP: Atlas.

Dejours, C., \& Bègue, F. (2010). Suicídio e trabalho: o que fazer? Brasília, DF: Paralelo 15.

Donham, K. J. (2010). Community and occupational health concerns in pork production: a review. Journal of Animal Science, 88(13), 2-11.

Empresa Brasileira de Pesquisa Agropecuária [EMBRAPA]. (2012). Agência de informação 
Embrapa: suínos. Recuperado de: http://www. agencia.cnptia.embrapa.br/gestor/suinos/ arvore/CONTAG01_6_1012200293742.html

Franco, T., Druck, G., \& Seligmann-Silva, E. (2010). As novas relações de trabalho, o desgaste mental do trabalhador e os transtornos mentais no trabalho precarizado. Revista Brasileira de Saúde Ocupacional, 35(122): 229-248.

Geng, Q., Torén, A., \& Salomon, E. (2009). Screening the working environment in outdoor pig systems. Journal of Agricultural Safety and Health, 15(3): 283-97.

Gudmundsson, G., \& Tómasson, K. (2009). General health in Icelandic farmers. Laeknabladid, 95(10), 655-659.

Heloani, R., \&Lancman, S. (2004). Psicodinâmica do trabalho: o método clínico de intervenção e investigação. Produção, 14(3), 77-86.

lanbukhtina, G.A., Masiagutova, L. M., \& Gainullina, M. K. (2011). Social and hygienic factors for health state in female poultry workers. Meditsina Truda i Promyshlennaia Ekologiia, (1), 29-34.

Kirychuk, S., Senthilselvan, A., Dosman, J. A., Zhou, C., Barber, E. M., Rhodes, C. S., \& Langley, R. (1999). Physical hazards of animal handlers. Occupational Medicine, 14(2), 181-94.

Lima, J. C. (2004). O trabalho autogestionário em cooperativas de produção: o paradigma revisitado. Revista Brasileira de Ciências Sociais, 19(56), 45-62.

(2009). Paradoxos do trabalho associado. Tempo Social, 21(1), 113-132.

Lima, J., Rossini, S., \& Reimão, R. (2010). Sleep disorders and quality of life of harvesters rural labourers. Arquivos de Neuro-Psiquiatria, 68(3):372-6.

Martinez, I. B., Lins, M. L., Pires, S. (2002). Cooperativas e revitalização dos espaços rurais: uma perspectiva empresarial e associativa. Cadernos de Ciências e Tecnologia, 19(1), 99-118.

Martinez, R., Gratton, T. B., Coggin, C., René, A., \& Waller, W. J. (2004). A study of pesticide safety and health perceptions among pesticide applicators in Tarrant County, Texas. Environmental Health, 66(6), 34-7.

Mendes, A. M. (2007a). Da psicodinâmica à psicopatologia do trabalho. In Mendes, A. M. (Org), Psicodinâmica do trabalho: teoria, método e pesquisas (pp. 29-48). São Paulo, SP: Casa do Psicólogo.

(2007b). Novas formas de organização do trabalho, ação dos trabalhadores e patologias sociais. In Mendes, A. M. (Org), Psicodinâmica do trabalho: teoria, método e pesquisas (pp. 49-87). São Paulo, SP: Casa do Psicólogo.

Mendes, A. M. B., \& Facas, E. P. (2011). Subjetividade e trabalho com automação. In Moraes, R. M., \& Vasconcelos, A. C. L. (Org.), Subjetivação e trabalho com automação: estudo no polo industrial de Manaus. Amazonas: Edua.

Mitloehner, F. M., \& Calvo, M. S. (2008). Worker health and safety in concentrated animal feeding operations. Journal of Agricultural Safety and Health, 14(2), 163-87.

Moraes, R. D. (2013). Estratégias de enfrentamento do sofrimento e conquista do prazer no trabalho. In Merlo, A. R. C., Mendes, A. M., \& Moraes, R. D. O sujeito no trabalho: entre a saúde e a patologia (pp. 73-92). Curitiba: Juruá.

Morgan, D. (1997). Focus group as qualitative research (Qualitative research methods series). London: Sege.

Oliveira, F. (2007). Os sentidos do cooperativismo de trabalho: as cooperativas de mão de obra à luz da vivência dos trabalhadores. Psicologia \& Sociedade, 19(1), 75-83.

Organização das Nações Unidas para a Alimentação e a Agricultura [FAO]. (2012). Cooperativas agrícolas alimentam o mundo. Recuperado de: https://www.fao.org.br/ download/WFD2012.pdf

Paraná. Secretaria de Estado da Agricultura e do Abastecimento [SEAB]. (2013). Suinocultura, análise da conjuntura agropecuária. Recuperado de: http://www.agricultura. pr.gov.br/arquivos/File/deral/Prognosticos/ SuinoCultura_2012_2013 
Périlleux, T. (2013). O trabalho e os destinos políticos do sofrimento (tradução Ricardo Avelar de Souza). In Merlo, A. R. C., Mendes, A. M., \& Moraes, R. D. O sujeito no trabalho: entre a saúde e a patologia (pp. 73-92). Curitiba: Juruá.

Pessoa, V. M., \& Rogotto, R. M. (2012). Agronegócio: geração de desigualdades sociais, impactos no modo de vida e novas necessidades de saúde nos trabalhadores rurais. Revista Brasileira de Saúde Ocupacional, 37(125), 65-77.

Receveur, T. (2005). Balancing animal well-being, cost, and employee health and safety in caging design and selection. Contemporary Topics in Laboratory Animal Science, 44(3), 68-71.

Rey, F. L. G. (2005). Pesquisa qualitativa e subjetividade: os processos de construção da informação. São Paulo, SP: Pioneira.

Sabroza, P. C., Leal, M. C., \& Buss, P. M. (1992). A ética do desenvolvimento e a proteção às condições de saúde. Cadernos de Saúde Pública, 8(1), 88-95.
Safin, V. F., Masiagutova, L. M., Khusnarizanova, R. F., \& lanbukhtina, G. A. (2009). Evaluation of health state and immune reactivity in female workers of pig-breeding enterprise. Meditsina Truda i Promyshlennaia Ekologiia, (11), 34-7.

Serviço Nacional de Aprendizagem do Cooperativismo [SESCOOP]. (2011). Panorama do cooperativismo brasileiro: ano 2011. Recuperado de: http://www.ocb.org. br/gerenciador/ba/arquivos/panorama_do_ cooperativismo_brasileiro__2011.pdf

Silva, A. R. (2007). O significado do trabalho na terra do fumo: perspectivas dos agricultores frente ao sistema integrado de produção industrial em Santa Cruz do Sul/ RS. Dissertação de Mestrado, Universidade de Santa Cruz do Sul, Santa Cruz do Sul, RS.

Singer, P. (2004). Cooperativas de trabalho. Recuperado de: http://www.mte.gov.br/ ecosolidaria/prog_cooperativatrabalho2.pdf

Von Essen, S., \& Donham, K. (1999). Illness and injury in animal confinement workers. Occupatioal Medicine, 14(2), 337-50. 


\section{Carmem Regina Giongo}

Mestre em Psicologia pela Universidade do Vale do Rio dos Sinos - Unisinos, São Leopoldo - RS. Brasil.

E-mail: ca.aiesec@gmail.com

\section{Janine Kieling Monteiro}

Doutora em Psicologia.

Docente da Universidade do Vale do Rio dos Sinos - Unisinos, São Leopoldo - RS. Brasil. E-mail: janinekm@unisinos.br

\section{Endereço para envio de correspondência:}

Rua Conselheiro D'Avila, 354, apto. 202. Jardim Floresta. CEP: 91040-450. Porto Alegre - RS. Brasil.

Recebido: 25/11/2013, Aprovado: 14/09/2015. 